\title{
PERIPHERAL GANGRENE IN MYOCARDIAL INFARCTION
}

\author{
BY \\ W. G. A. SWAN AND C. B. HENDERSON \\ From the Cardiovascular Department, Newcastle General Hospital
}

Received January 23, 1950

Peripheral gangrene caused by the extreme vaso-constriction that accompanies severe circulatory failure in such a disease as cholera is well recognized. Its occurrence, however, as a complication of myocardial infarction is such an uncommon event, to judge from the literature, that the reporting of two cases seems to be justified.

\section{CASE REPORTS}

Case 1. The patient was a married man of 53, a hairdresser. For two years he had complained of retro-sternal and epigastric pain brought on by exertion and relieved by rest. Before this he had been in good health.

On December 24, 1948, he was seized with severe pain behind the sternum and in the epigastrium accompanied by shortness of breath and flatulence. His doctor made a diagnosis of coronary thrombosis and gave him morphine of which he received in all two and a half grains at home. His condition did not improve and he was admitted to hospital on December 28th.

On admission he was severely dyspnœic at rest. There was no œdema. He was pale and it was noted that the end of his nose was blue and cold. The pulse was impalpable at the wrist and the blood pressure was $80 / 60$. The apex rate was 100 a minute and the rhythm was regular. The heart showed no clinical enlargement and the heart sounds were normal. There was no pericardial friction. There were loud moist sounds all over both lungs, especially towards the bases. The liver was not enlarged.

He remained seriously ill with a heart rate of around 110 a minute until December 30th, when he seemed to be a little better, but it was found that the right foot had become cold and blue up to the level of the ankle, and was anæsthetic over the same area. No pulse could be felt at the ankle, though the femoral pulses were present on both sides. On this day also it was noted that the whole of the nose was blue, livid, cold and anæsthetic, and that there was a clear line of demarcation with the normal skin at the base of the nose. The tips of the ears and the tongue were unaffected, but there were some blotchy blue areas on the hands. The fingers were unaffected. Anti-coagulant treatment was started on this day.

On December 31st, the left foot became affected in exactly the same way, and the right foot remained blue, cold and anæsthetic. The prothrombin time was 36 seconds and a normal control was 25 seconds.

He remained gravely ill, and on January 3, 1949, a blood pressure reading of $60 \mathrm{~mm}$. systolic with no diastolic end point was made: he died on this day. Electrocardiograms on the fourth and tenth day of the illness showed evidence of extensive myocardial infarction (Fig. 1).

Necropsy. There was gangrene of the nose with a well-defined line of demarcation, and small bullæ over the healthy skin at the junction. Both feet showed gangrene, with the skin black, swollen, and wrinkled (Fig. 2). The fingers and ears did not show gangrene. 




A

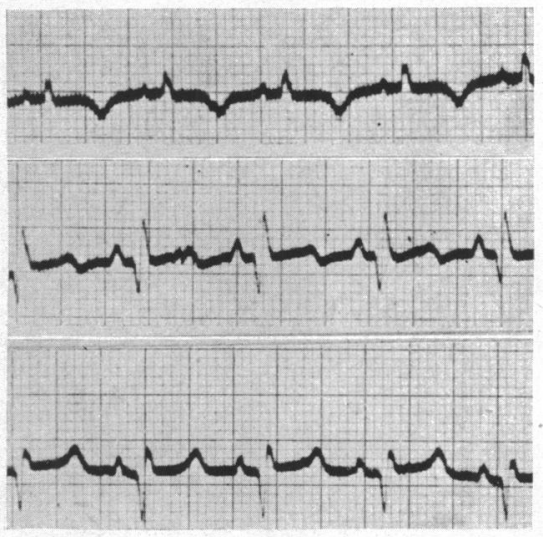

B

Fig. 1.-Case 1. Electrocardiograms. (Præcordial leads omitted.) (A) Fourth day of illness. (B) Tenth day of illness.

The pleural cavities contained an excess of blood-stained fluid. The lungs showed congestion and œdema of the bases with patches of bronchopneumonia. The pericardial cavity contained a slight excess of fluid.

The heart was of average size. There was no pericarditis. All the valves were healthy. There was a large area of recent infarction involving the anterior, lateral and posterior parts and also the inter-ventricular septum. There was widespread ante-mortem thrombosis adherent to the endocardium of the left ventricle (Fig. 3).
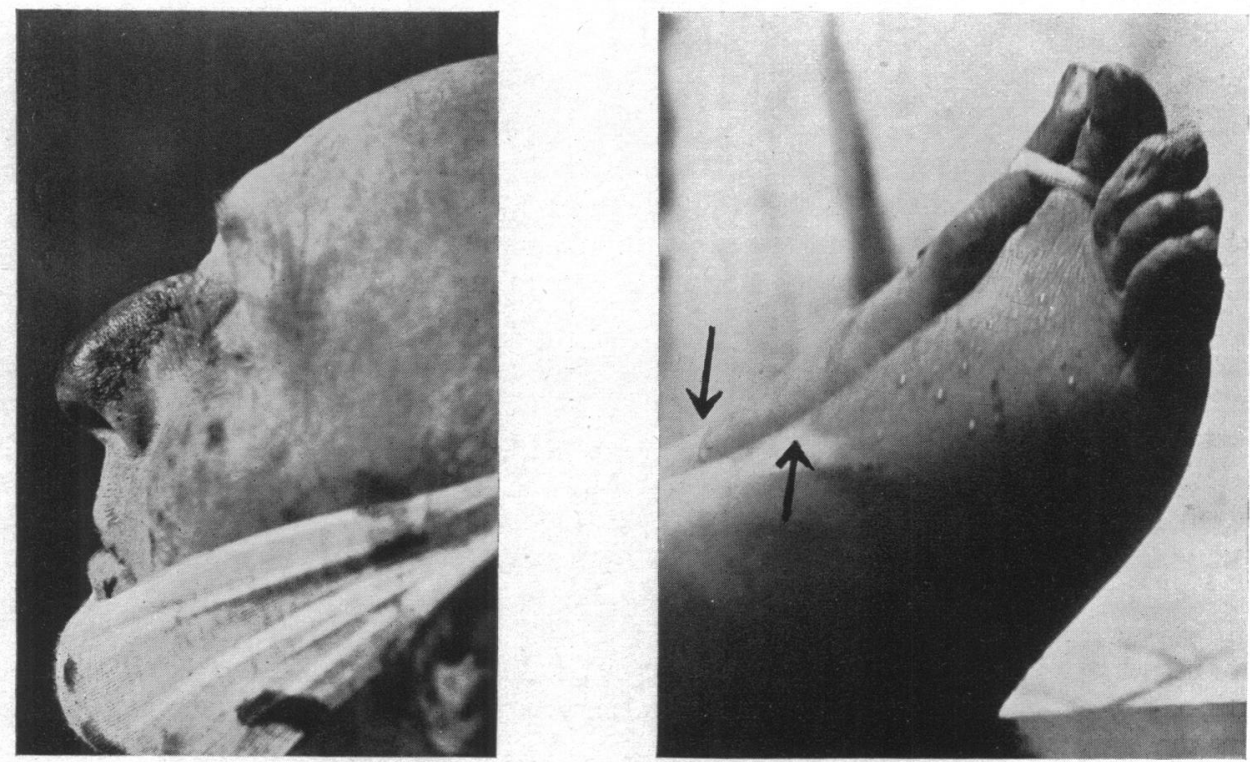

Fig. 2.-Case 1. After death, showing gangrene of the nose and feet. Arrow shows edge of gangrenous area. 


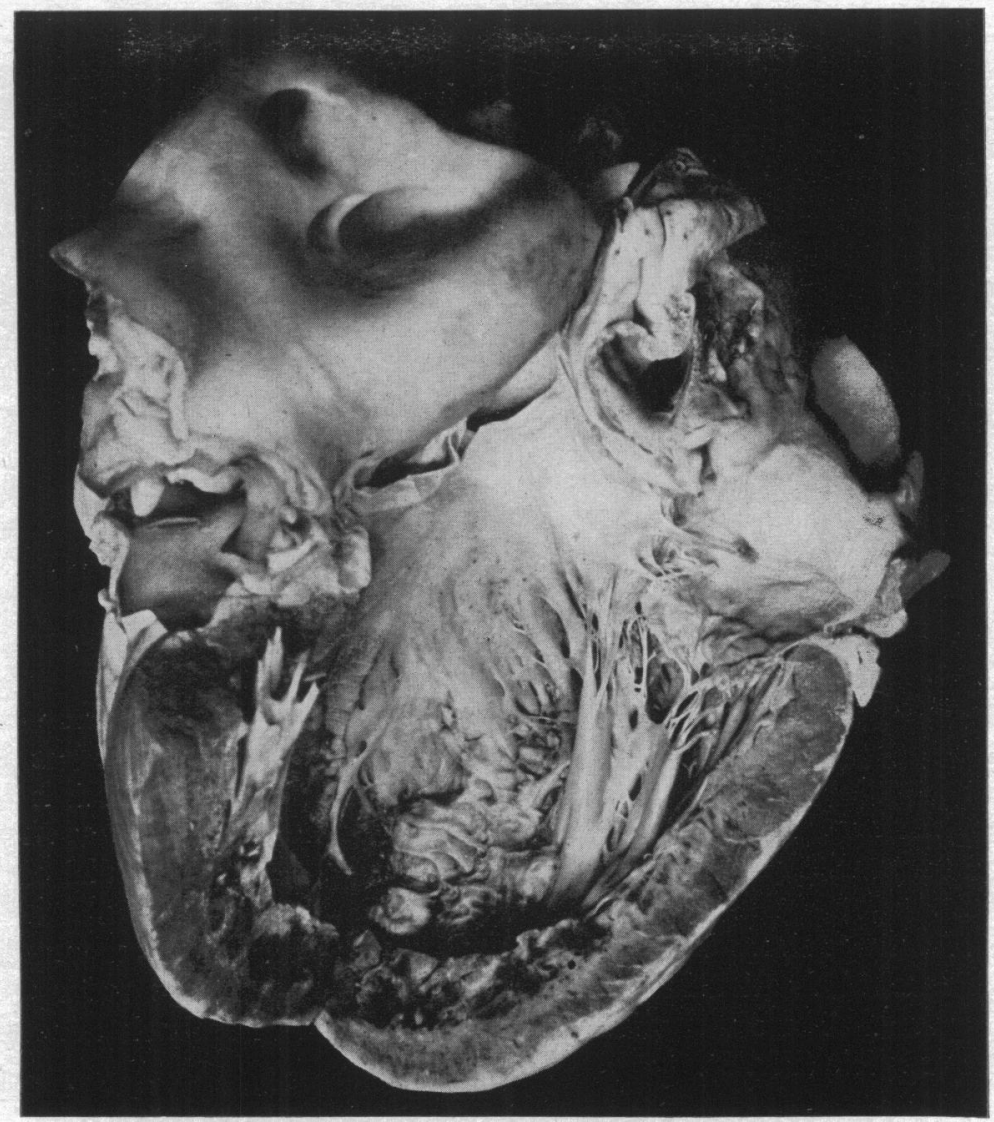

Fig. 3.-Case 1. Left ventricle opened to show extensive recent infarction and ante-mortem intracardiac thrombosis.

The left coronary artery showed a recent thrombus completely occluding the lumen distal to the origin of the descending branch, which was itself completely obliterated by atheroma at its origin. The circumflex branch was greatly narrowed by atheromatous degeneration. In the right coronary artery there was a very recent thrombus completely occluding the lumen just proximal to the origin of the inferior interventricular branch.

The aorta was free from atheroma. The abdominal viscera showed passive venous congestion but no other naked-eye abnormality.

Dissection of the femoral, popliteal, peroneal, and posterior tibial arteries as far as the ankles and the dorsales pedis and lateral plantar arteries on both sides revealed no evidence of thrombosis or of embolism, and there was no naked-eye evidence of intimal degeneration in these vessels.

Case 2. A housewife of 63 had for 15 years been subject to attacks of numbness of the fingers when exposed to cold and stated that her toes were always cold. There was no history of any serious illness in the past.

Two months before the onset of her illness she had a short attack of faintness and rapid irregular heart action. A fortnight later there was another attack of palpitation associated with a tight feeling in the epigastrium. She went very pale and vomited. After this she noticed marked shortness of breath.

One day before admission, while in bed, a very severe pain developed in the centre of the upper 
part of her chest radiating through to the back and into the shoulders and both sides of the neck. The pain was like a tight band round the chest. She became very short of breath, broke out into a sweat and went pale. The pain lasted, severely, for four hours and an ache remained for twenty-four hours.

She was admitted to Dryburn Hospital, Durham, on April 18, 1949. On admission she was noted to be very ill, very dyspnœic and slightly cyanosed. The heart rate was 102 , regular with extrasystoles, and the blood pressure was 140/90. Obesity prevented accurate cardiometry, but the heart sounds were normal. Numerous rales were present in the chest, and the liver was palpable and tender. The jugular veins were distended.

The fingers and toes were blue and cold, but the rest of the hands and feet were warm. The radial and dorsales pedis pulses were palpable on both sides. Sensation was blunted over the tips of the digits but was normal elsewhere.

Progress. She became worse rapidly. On April 21 the tip of the nose was noted to be blue, and there was extension of the cyanosis of the fingers and toes.

An electrocardiogram on April 21 (Fig. 4) showed depression of the S-T period in lead I, biphasic $\mathrm{T}$ in lead II and deep Q with elevation of S-T in lead III. Chest leads not taken.

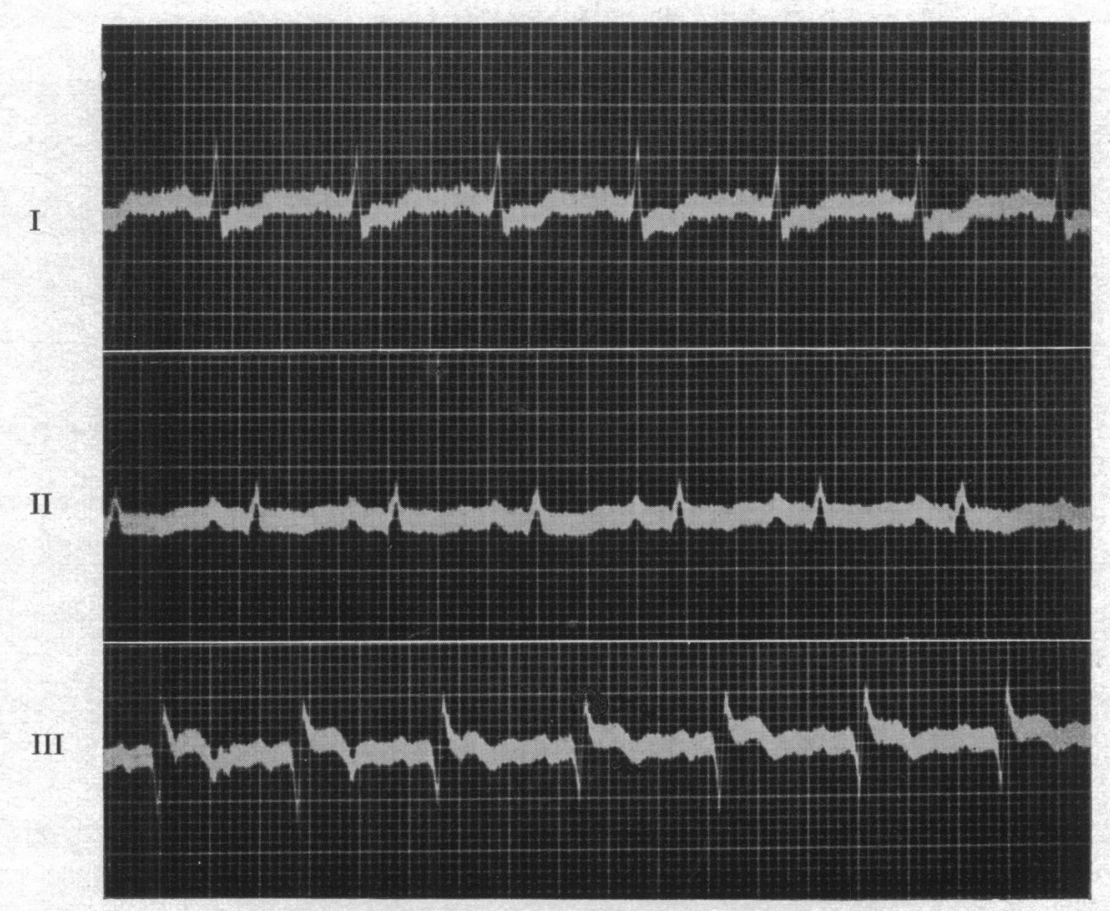

FIG. 4.-Case 2. Electrocardiogram on fourth day of illness.

A blood examination on April 20 showed E.S.R. $24 \mathrm{~mm}$. in one hour, hæmoglobin $11 \cdot 2 \mathrm{~g}$. , and white cells 11,000 per c.mm. The Wassermann reaction was negative. The urine contained albumen but no sugar.

Anti-coagulant treatment with heparin and dicoumarol was given between April 23 and May 5 .

She was transferred to Newcastle General Hospital on May 13. The physical signs were the same, except that there was slight odema of the ankles, but no cyanosis. The blood pressure was 125/85. There was no obvious enlargement of the heart, and the heart sounds were normal. There 
were a few rales at the lung bases. There was right subcostal tenderness, but the liver could not be palpated.

There was a dry scab on the tip of the nose with a surrounding area of hyperæmia. The lobes of the ears and the tip of the tongue were normal. The index finger of the left hand was blue and cold, but there was no gangrene; the rest of the hand was normal and the radial pulse was palpable. There was dry gangrene of all the digits of the right hand, which extended well up onto the hypothenar eminence; the radial pulse was palpable. There was dry gangrene of all the toes except the right little toe. The dorsales pedis and posterior tibial pulses were palpable on both sides (Fig. 5).

An electrocardiogram showed depression of S-T in lead I, a flat T in lead II, and deep Q, elevated S-T, and inverted T in lead III. Chest leads showed a low voltage T from V4 to V6.

On July 5 there was persisting QIII, TIII pattern.

On December 7 lead I was now normal with persisting QIII, TIII pattern, but T waves in V4-6 now well upright.

Progress. Her general condition improved steadily with disappearance of the odema and cyanosis in a few weeks. The gangrenous patch on the tip of the nose quickly separated leaving a smooth, slightly depressed scar. The toes separated slowly and fell off at the distal inter-phalangeal joints with good healing. The fingers of the right hand all separated with the exception of the thumb which is still adherent at the time of writing. A healing surface has been left in all areas. The patient is now ambulant, comfortable, and cheerful, eight months after the attack. Several episodes of pallor and cyanosis of the left hand have been observed during her long stay in hospital. Screen examination showed a transverse heart of normal size and shape.
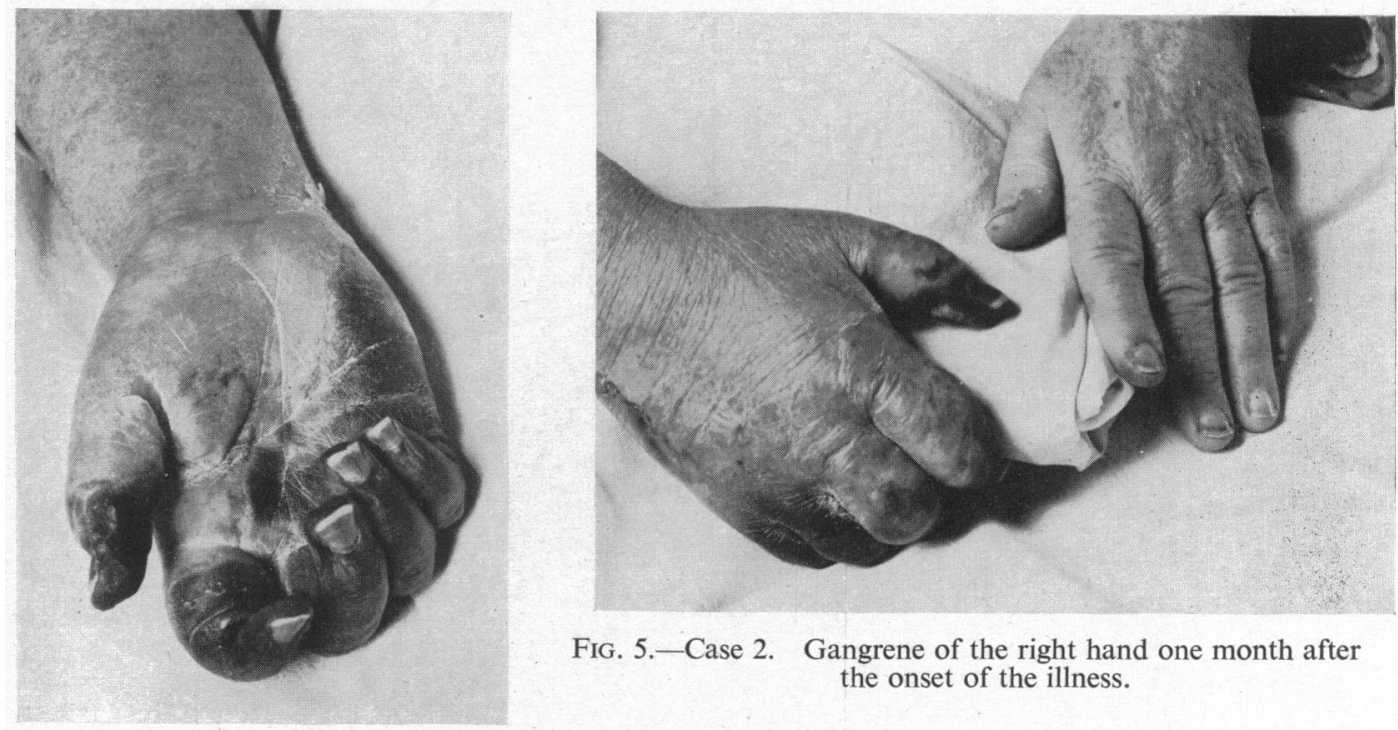

FIG. 5.-Case 2. Gangrene of the right hand one month after the onset of the illness.

\section{Discussion}

The occurrence of peripheral gangrene in acute heart failure is an uncommon but recognized event. Perry and Davie (1939) report a case of hypertensive heart failure in a man of 64 in which both feet became gangrenous very shortly before death, and in which no obstruction of the iliac, femoral, or popliteal arteries could be demonstrated. Fishberg (1946) states that he has seen peripheral gangrene as a rare complication of myocardial infarction, and Abrahams (1948) describes incipient peripheral gangrene in a case of paroxysmal tachycardia.

A possible explanation of the phenomenon is advanced by Fishberg (1938) who observed the 
co-existence of engorged jugular veins with collapsed veins in the extremities in cases of extreme failure of the right heart. He found by direct measurement that the jugular venous pressure might be as high as $20 \mathrm{~cm}$. of water while at the same time the pressure in the antecubital vein was under $1 \mathrm{~cm}$. With improvement, which was exceptional, the antecubital pressure rose to that in the jugular vein. The phenomenon was interpreted as a manifestation of vasoconstriction in the extremities, evoked probably reflexly by extreme diminution of cardiac output, in other words an analogue in heart failure of what was long ago demonstrated in experimental shock. The selective vasoconstriction is said to result in a redistribution of blood, a smaller portion of the cardiac output going to the limbs, and a larger portion to the brain and presumably to the other viscera. Symmetrical gangrene was observed twice. The writer suggests that the rare peripheral gangrene of heart failure is angiospastic in origin.

The gangrene of the legs in our Case 1 might reasonably be attributed to embolism, especially as there was intracardiac thrombosis, but a careful search of the arteries of the lower limbs failed to reveal such embolism, and this, coupled with the fact that there was gangrene of the end of the nose at a comparatively early state of the illness, leads us to conclude that intense vasoconstriction, following massive myocardial infarction, was the explanation of the gangrene in all the observed situations.

In Case 2 there was a history of attacks of Raynaud's disease before the myocardial infarction took place and this was confirmed by the observation of typical coldness, blanching, and cyanosis of the hands on several occasions afterwards. It is suggested that the very extreme degree of peripheral gangrene which occurred in this case, involving as it did the tip of the nose, the greater part of one hand and nine toes, was caused by an extreme degree of vasoconstriction following a myocardial infarction in a patient subject to Raynaud's disease.

\section{SUMMARY}

Two cases are described in which gangrene of the nose and of the limbs followed a myocardial infarction. In one case, a subject of Raynaud's disease, recovery occurred after the loss of much tissue. It is suggested that the gangrene which may occur as a rare complication of severe heart failure is caused by intense and prolonged peripheral vasoconstriction.

\section{REFERENCES}

Abrahams, D. G. (1948). Brit. Heart J., 10, 191.

Fishberg, A. M. (1938). J. Clin. Invest., 17, 510.

(1946). Heart Failure, London, p. 656.

Perry, C. B., and Davie, T. B. (1939). Brit. med. J., 1, 15. 